\title{
CTN: Advancing Rural and Underserved Healthcare in California
}

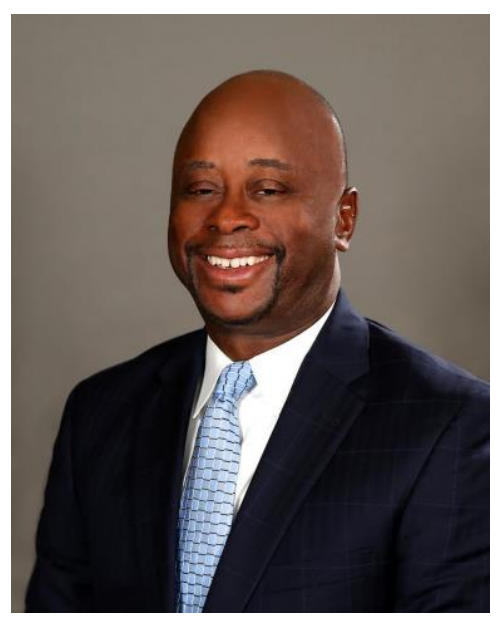

Mr. Eric Brown

Editor's note: In this TMT interview, Mr. Eric Brown, President and CEO of the California Telehealth Network (CTN), discusses the development and the role of CTN in providing advanced information technologies and services to medically underserved and rural Californians.

An independent non-profit 501c3, CTN is one of the largest FCC-funded statewide telehealth networks in the nation, connecting over 750 healthcare provider locations.

Telehealth and Medicine Today encourages our readers to download this audio presentation. You many listen to it and share it with your colleagues at your convenience. Reproduction of the interview is encouraged, with attribution to Telehealth and Medicine Today, 2016, URL .

TMT: Mr. Brown, please provide a brief overview of CTN, the California Telehealth Network. [00:00 min]

Eric Brown: We operate a nonprofit organization that forms a consortium for about 
three hundred safety net clinics and hospitals around the state-both rural and urban areas. Generally, they are medically underserved, and by that I mean there may be patient populations but not very many doctors.

TMT: Can you give an example of CTN's funding sources? [00:27 min]

Eric Brown: We participate in the FCC (Federal Communications Commission) rural health care program, the Health Care Connect Fund, which allows us to obtain broadband discounts for our clinics and hospitals so that they can have more robust broadband connectivity. And most of them are interested in doing that so that they can set up live virtual consultations over a broadband connection, so that a patient in the local community can be seen by the first available specialist anywhere in the state.

TMT: CTN is advancing healthcare through "connectivity." Please describe how that is done? [01:07 $\mathrm{min}]$

Eric Brown: In terms of connectivity we serve all flavors of healthcare providers, but predominately for the federal subsidies that we pass on broadband, they're generally available for nonprofit or public or tribal health clinics and hospitals-those that serve the under-served high Medicare or Medicaid patient population.

TMT: How do consumers join the CTN? (01:38 min)

Eric Brown: We generally provide the site outreach. We go out and find them. Most of them aren't really familiar with these programs and that they exist as evidenced by the fact that the Health Care Connect fund, that I mentioned, has been under subscribed. It never spent more than half of the $\$ 400$-million-dollar allocation.

So, we do the site outreach, to go out and make the sites aware, and then we take it from there to confirm their eligibility with the folks in Washington. And once they've been confirmed as eligible we assist with the actual ordering of the circuits from broadband providers, and we process the billing so that they don't have to do that with the folks at the FCC (Federal Communications Committee). 
TMT: CTN has assisted in developing 10 rural telemedicine networks. How did that come about? (02:31 min)

Eric Brown: CTN was initially formed and incubated at UC Davis Health System in Sacramento. UC Davis has been a leader in deploying telemedicine in the Northern California region; and they applied for and received a grant through NTIA (National Telecommunications and Information Administration) a broadband technology opportunities program grant (a VTOP grant it is referred to), and it did a couple of things.

It provided the initial seed capital to get the organization started in terms of personnel and travel and those kinds of things. It also allowed CTN to work with UC Davis to set up ten of what we called Model Communities that received grants funds to deploy telehealth equipment to meet the needs of each community.

So, in some cases they requested and received telemedicine carts and codecs (a device or computer program for encoding or decoding a digital data stream or signal) and peripherals. In other cases, they may have needed switching gear in their hospitals and clinics. We allowed them to tell us what their needs were, and then the grant provided the equipment they needed. And so that was really our first foray into working with local communities. Some were urban, as in Los Angeles and the Bay Area, but the majority of them were in rural California-very small towns.

TMT: Please give an example of a rural area served and what that entails? [04:16 min] Eric Brown: A good example would be Portola up in the eastern Sierras, about four thousand people. There's a critical access hospital there that is about two and a half to three hours away from the nearest tertiary care hospital, which would be either in Sacramento or Reno.

So, telemedicine equipment and broadband connectivity are very important for them to be able to consult with specialty care physicians in Sacramento or Reno, and in doing an initial diagnosis. And, depending on how that goes, the decision can be made whether or not the patient actually needs to travel to the larger community to receive 
care.

TMT: What are the major challenges faced when initiating telemedicine networks? [05:10 $\mathrm{min}]$

Eric Brown: The challenges in serving rural telehealth networks are pretty formidable. First and foremost is the need for broadband, and reliable broadband, which can be expensive. Most of the broadband providers charge a distance charge. So, the same feed circuit that you might get in downtown San Francisco could be five times the price in one of these rural communities - if they have availability at all. So that's the first challenge is making sure that they can get connectivity at an affordable price. Here again, that's where the FCC broadband subsidies come in.

Right behind that, once they are connected making sure that they have the equipment they need-the video conferencing equipment. And we also have been able to help with grant funding, generally to meet that need in rural communities. Last year, we were recipients of one of the USDA Rural Utility Service grants that help to serve eight rural clinics around the state_-telehealth equipment and support.

And once they get equipment, it's a challenge to help them identify where they can find the specialists that they need that will offer their services via telemedicine. And very often physician providers, depending on state that you're dealing with, may not have access to the same reimbursement that they do for in-person visits. Here in California, CTN worked with the stakeholder partners to get one of the first statewide laws passed in 2010 that provided that telehealth visits would be compensated or reimbursed on same basis as impersonal visits.

TMT: Is it becoming easier to access broadband for CTN programs? [07:10 min] Eric Brown: I would say the broadband challenges are getting better, because broadband is becoming more ubiquitous. But in the more rural and kind of frontier areas it's still a significant challenge. 
TMT: How do you gauge the success of a program? [07:24 $\mathrm{min}$ ]

Eric Brown: We gauge the success of telemedicine programs by monitoring the activity levels at our sites. We are fortunate in that our sites report to us on a monthly basis, how they are using our telehealth network. In any given month, and then more recently, we'll see $50 \%$ to $60 \%$ of the sites are engaged in doing live virtual consultations over the network. A vast majority of those in California right now are behavioral health consultation; and we are now beginning to go further into understanding the impact of the availability of these specialty care services on patient outcomes.

TMT: Do the rural sites find it difficult to keep up with the additional administrative responsibilities associated with a rural telemedicine program? [08:08 $\mathrm{min}$ ] Eric Brown: The rural sites are administratively challenged. So it's all they can do to just keep up with the demands of taking care of their patients. When you then try to overlay that with getting them the report to you on patient outcomes, and pulling that out of various electronic health record systems, it's still quite a challenge; but we think we have identified some solutions that can help us better automate that process so that we can do a better job of quantifying what the patient outcome impact is of having telemedicine available in a community or at a clinic or hospital.

TMT: What are CTN's reporting responsibilities to the agencies that provide the grants? [08:52 min]

Eric Brown: What the government wants to see depends on the agency. I think when we're talking about the Federal Communications Commission, they want to see how many new sites are utilizing the subsidies that they offer, and there is a very clear emphasis on rural sites; and they want to see the dollars are having a positive impact on expanding broadband availability in those rural safety net clinics and hospitals.

I think when you talk to the folks at the Health Resources and Human Services Agency or HERSA, they're more interested in the clinical outcomes and what's happening to patient health and population health when patients who are in traditionally medically underserved or rural areas all of a sudden have access to better specialty care. Do we 
see an improvement in their health outcomes? So it kind of depends on the agency.

We're interested in all of that because our mission, as a nonprofit, is to use broadband and health information technology to expand access to care so we delve in both of those areas.

TMT: Does CTN have direct involvement in staff training? [10:08 min]

Eric Brown: We do get involved in training the staffs of these clinics and hospitals.

We're fortunate in California that we have one of the 12 regional telehealth resource centers. It's called the California Telehealth resource center and it's funded by HERSA to foster telehealth awareness and adoptions.

So, whether you're a safety net clinic or hospital, a health plan, or an academic medical center, or just a private independent physician, these regional telehealth resource centers are there to provide orientation of what telehealth is, to provide technical assistance as the healthcare providers make the decisions about what equipment they need, how to configure their exam rooms, what are the clinical workflows that have to occur to make telehealth work.

So, we always knew that technology was just a small piece of the challenge of expanding access to care. Ultimately, it's about training the clinicians and staffs of clinics and hospitals to be comfortable using the technology. We provide a lot of input to the technology providers the equipment companies based on what we hear from our sites to make sure that solutions are as turnkey as possible. Because one thing we know, the doctors and nurses don't have a lot of time and patience to fiddle with a lot of knobs. It's got to work, and its got to be fairly easy to use them. So, yes, we're very involved on the training front.

TMT: How many states offer a service similar to the service provided by CTN? [11:41 $\min ]$

Eric Brown: Going back to the FCC Healthcare Connect Fund that we participated in, 
last time I checked there were about 30 states that had either regional or statewide telehealth networks. We are seeing that in some cases these networks are stretching across state boundaries. So, it is a trend that's growing, and they are seeing an acceleration in the number of applicants to form networks.

TMT: What is the future for CTN? [12:11 min]

Eric Brown: I think as far as the future for the California Telehealth Network, with the expansion of the Affordable Care Act here in California and Medicaid expansion (we call it Medical in California) there's no doubt that, depending on whose numbers you use, there are four million more people with health coverage that didn't have it before. And that is putting an increased demand on the health plans and providers to find specialty care physicians that can take care of the increased patient loads. And very often those specialists aren't located in the same communities where the patients are. And very often vulnerable patient populations don't have the wherewithal: the transportation, the money to perform a lot of follow up visits at the doctor's not located nearby.

And so we're seeing a lot of growth in demand for our services, both the infrastructures broadband, and equipment services, and consulting, but also the implementation and training for telehealth for various organization; and that includes health plans, that include county health organizations that are trying to meet the demands of the patients that are showing up in their local clinics. And as time goes on we expect those trends to continue.

TMT: Based on your experience, what is the future of telemedicine in the United States? [13:31 min]

Eric Brown: We're witnessing a real change in how healthcare is going to be delivered in the United States, and I tell people that in a similar fashion other industries like banking or financial services have changed. I remember as a kid we needed money from the bank you physically got in a car and you went down to the bank and wrote a check gave it to the teller and that's how you get your money. 
Needless to say that's not how most people access cash nowadays, and I think when you look at the future of how healthcare will be delivered, particularly for the more routine medical condition don't require a high acuity physician or surgery or anything of that nature, you're going to see more of those interactions move to telehealth and telemedicine; and our job here at CTN is to continue to grow awareness and help advise the clinics and hospitals how they can get on board. And we're seeing a very receptive marketplace to that.

Tags: Affordable Care Act, broadband, California Telehealth Network, CTN, Eric Brown, FCC, Federal Communications Commission, Health Care Connect Fund, Health Resources and Human Services Agency, Healthcare Connect Fund, HERSA, hospital, Medicaid, medical, Medicare, model communities, National Telecommunications and Information Administration, nonprofit, NTIA, outreach, Portola, rural health care, safety net clinics, tribal health, UC Davis Health System, USDA Rural Utility Service, video conferencing, virtual consultation

Eric Brown is the President and CEO of the California Telehealth Network. Mr. Brown is an experienced manager in the telecommunications industry, and a 15-year veteran of the cable television industry. He combines senior-level experience in cable network affiliate relations and experience in managing multiple broadband system marketing and operations. Mr. Brown served as past Chairman of the California Cable and Telecommunications Association (CCTA), and he is a recipient of the prestigious National Cable \& Telecommunications Association Vanguard Award for excellence in cable operations and the cable industry's CTAM Chairman's Award for excellence in cable marketing. 